\section{Sentidos e usos da fome no debate político brasileiro: recorrência e atualidade}

\author{
Meanings and uses of hunger in Brazil's political \\ debate: recurrence and presence
}

\author{
Empleo y sentido del hambre en el debate \\ político brasileño: recurrencia y actualidad
}

Fernanda Ribeiro dos Santos de Sá Brito 1

Tatiana Wargas de Faria Baptista 1

\section{Resumo}

A fome é uma questão persistente e estrutural no Brasil, ocupando espaço na agenda politica de tempos em tempos, em especial em momentos de crise politica. Mas quando se torna interessante denunciar a fome? Quem enuncia o problema e de que modo? $O$ artigo discute os diferentes usos retóricos e sentidos associados à fome no debate politico brasileiro no período de 1986 a 2015 e lança luz sobre a reatualização do debate a partir de 2016. Trata-se de um estudo de análise de políticas que visa subsidiar a reflexão sobre as estratégias e objetivos das politicas públicas recentes de combate à fome no Brasil. A pesquisa analisou documentos relacionados à fome referidos à politica governamental de 1986 a 2015, revelando diferentes sentidos de fome acionados politicamente em momentos distintos do contexto brasileiro: a fome vista como carência nutricional, pobreza, miséria, injustiça social, desigualdade, insegurança alimentar grave. Quanto aos usos politicos, a fome foi mobilizada retoricamente por diferentes atores, conforme o cenário de disputa política, até praticamente sumir do debate, retornando a partir de uma nova crise no ano de 2016. Esse retorno também diz respeito ao não enfrentamento de desigualdades estruturais. Quando a fome perdeu espaço na agenda politica, fragilizou-se também a política de segurança alimentar e nutricional e muitas conquistas retrocederam. Conclui-se que a retórica politica mobiliza auditórios, sendo importante manter a pauta de combate à fome no debate politico enquanto existirem pessoas passando fome no país, e que essa deve ser uma agenda central para garantia da segurança alimentar e nutricional.

Fome; Insegurança Alimentar; Segurança Alimentar; Política Pública

\author{
Correspondência \\ F. R. S. S. Brito \\ Rua Barão do Bom Retiro 316, Rio de Janeiro, RJ \\ 20715-003, Brasil. \\ fernandasabrito@gmail.com \\ 1 Escola Nacional de Saúde Pública Sergio Arouca, Fundação \\ Oswaldo Cruz, Rio de Janeiro, Brasil.
}




\section{Introdução}

Em 2014, o Brasil saiu do Mapa da Fome da Organização das Nações Unidas (ONU) 1, ao apresentar menos de $5 \%$ da população em situação de subalimentação. A Pesquisa Nacional por Amostra de Domicilios (PNAD) 20132 mostrava que 3,2\% dos domicílios, 7,2 milhões de pessoas, se encontravam em insegurança alimentar grave, o que configura fome, segundo a Escala Brasileira de Insegurança Alimentar (EBIA).

A importante conquista brasileira contrastava com o quantitativo de pessoas em insegurança alimentar grave (7,2 milhões), superando a população de muitos países. E, apesar do Brasil estar classificado como um país de alto desenvolvimento humano, ainda se posicionava em 2014 entre os dez países mais desiguais do mundo ${ }^{3}$.

Os dados sobre a concentração de renda no país são reveladores dessa persistente desigualdade. O rendimento médio mensal real de 1\% da população com maior renda em 2018 correspondia a 33,7 vezes o rendimento de $50 \%$ da população com menor renda ${ }^{4}$. Os $10 \%$ da população com menor renda detinham apenas $0,8 \%$ dos rendimentos, enquanto os $10 \%$ com maior renda detinham $42,9 \% 4$. Conforme Souza 5 , a concentração de renda entre o $1 \%$ mais rico da população não sofreu mudanças substantivas de 1926 a 2013, permanecendo num patamar muito alto na maior parte do tempo. As características dessa perversa desigualdade não mudaram substantivamente nesse período e o esforço de combatê-la nos diferentes momentos da história brasileira, ainda que tenha proporcionado alguma redistribuição de renda, ocorreu somente entre os estratos inferiores e não logrou romper com a estrutura de poder dos mais ricos 5 .

A PNAD 20132 também aponta que a insegurança alimentar acometia especialmente negros, mulheres e crianças. No mesmo ano, uma pesquisa realizada em 169 comunidades quilombolas 6 revelava que $55,6 \%$ dos adultos e $41,1 \%$ das crianças vivenciavam situações cotidianas de fome. No Baixo Amazonas, a cada cinco residências, quatro possuíam crianças passando fome 6 .

As dimensões continentais do Brasil parecem contribuir para invisibilizar o problema e o não enfrentamento das desigualdades torna a fome uma questão persistente e estrutural no Brasil, consequência da manutenção de injustiças sociais que retornando à agenda política desde a Primeira República, especialmente em momentos de crise política, como: entre 1930-1940, com o desabastecimento de alimentos decorrente da guerra ${ }^{7}$ e o debate acerca das condições estruturais do país e a fome 8 ; no final da década de 1970 e anos 1980, num cenário de elevados índices de miséria e desnutrição ${ }^{9}$; no início da década de 1990, com o Mapa da Fome contabilizando 32 milhões de famintos 10; no início dos anos 2000, com a persistência da fome e desigualdades 11; a partir de 2016, com o "retorno da fome" após políticas de ajuste e restrição de gastos em políticas sociais 12,13,14.

O fato da fome tornar-se recorrente no debate político indica que as soluções encontradas não foram suficientes. Questiona-se: Quando se torna interessante denunciar a fome? Por que ocupa o espaço da agenda pública só em alguns momentos da história brasileira? Quem enuncia o problema e de que modo?

O objetivo deste artigo é discutir os diferentes usos retóricos e sentidos associados à fome no debate político brasileiro no período de 1986 a 2015 e lançar luz sobre a reatualização do debate a partir de 2016. Trata-se de um estudo de análise de políticas que visa subsidiar uma reflexão sobre as estratégias e objetivos das políticas públicas recentes na construção de uma agenda de combate à fome no Brasil.

\section{Metodologia}

Palavras e enunciados remetem a signos, significantes, significados. Há uma diversidade de significados para fome: sensação de vazio ao passar horas sem alimento; completa privação do alimento 15; e até a vontade subjetiva de obter algo ${ }^{16}$. No debate político, essa palavra está associada a diferentes argumentos, num uso retórico para convencimento e adesão a projetos.

A pesquisa consistiu na análise de documentos relacionados à fome referidos à política governamental de 1986 a 2015. Foram selecionados documentos do Poder Executivo e de organizações não 
governamentais (ONG); relatórios de conferências; relatório de Comissão Parlamentar de Inquérito (CPI) do Congresso Nacional e documentos de campanhas presidenciais.

Identificamos diferentes momentos de discussão da fome no contexto político: 1986-1994, com a reinserção da fome no debate político; 1995-2002, com a fome perpassando a disputa de dois projetos políticos distintos para o país; 2003-2010, quando a fome assume centralidade na agenda de governo; 2011-2015, quando a agenda de combate à fome situa-se num projeto maior de enfrentamento da miséria e pobreza (Quadro 1). Após 2015, ocorreram fatos políticos relevantes que acentuaram a fome no país e foram incluídos na discussão.

Trazemos os sentidos da fome como uma construção social 17 , um empreendimento coletivo e interativo que ocorre na dinâmica das relações sociais a partir da compreensão que as pessoas têm das situações e fenômenos ao seu redor. Assim, identificamos as práticas discursivas como produtoras de realidades. Na leitura dos documentos, localizamos as palavras "fome" e "segurança alimentar" e sinônimos, buscando identificar os sentidos da fome em seu contexto e o que criaram de repertórios interpretativos/argumentativos.

Quanto ao uso retórico da fome, cada documento foi analisado em seu propósito, com identificação do auditório, argumentos e contexto, entendendo a retórica como uma construção argumentativa para convencimento de grupos 18 .

Para acompanhar a análise de cada momento, remetemos ao Quadro 1 e à Figura 1.

\section{O debate político sobre a fome na redemocratização (1986-1994)}

No começo da década de 1980, o Brasil era a 8a economia do mundo e o 4o exportador de alimentos. Também era denunciado como 6o lugar em subnutrição, com 86 milhões de subnutridos e meio milhão de crianças morrendo de fome por ano 19 . O cenário exigia mudanças e apontava-se para a necessidade de transformação da estrutura agrária e da política de emprego, bem como de uma distribuição mais equitativa de renda e alimentos 19 , buscando atender as necessidades da população.

O governo da Nova República inicia com o desafio de combater as desigualdades e garantir a estabilização econômica. Mas esses eixos não se mostraram convergentes. Na política econômica, prevaleceu a preocupação com o controle da inflação, sem uma estratégia mais efetiva para inclusão e redistribuição ${ }^{20}$. Na área social, a mobilização voltava-se para incorporação de direitos na nova Carta Constitucional. A fome era pauta do movimento sanitário, que, desde o final dos anos 1970, trazia a perspectiva do conceito ampliado de saúde, englobando o debate de várias áreas sociais, incluindo alimentação 21 .

A VIII Conferência Nacional de Saúde (1986) foi a expressão maior desse movimento e teve como desdobramento a realização de conferências específicas, como a I Conferência Nacional de Alimentação e Nutrição (I CNAN). Nela foi retratada a "grave situação alimentar e nutricional do país" 22 (p. 2) e a ênfase esteve nas carências nutricionais. Debateu-se a importância da qualidade do alimento e utilizou-se a expressão segurança alimentar e nutricional 22,23, avançando na indicação dos pré-requisitos para acesso a uma alimentação adequada: reforma agrária; política agrícola para alimentos básicos; e política socioeconômica, visando ampliar riqueza e redistribuir renda 22.

A I CNAN recomendou a criação de um Conselho Nacional de Alimentação e Nutrição e um Sistema de Segurança Alimentar e Nutricional como estratégia de enfrentamento da fome. Contudo, não logrou alcançar a agenda governamental.

A década de 1990 inicia num novo contexto, com um governo aderido às ideias liberais. Fernando Collor redirecionou o país no sentido antiestatal e internacionalizante, adotando medidas que aprofundaram a crise e frustraram as expectativas das forças políticas presentes ${ }^{9}$, especialmente em relação às políticas sociais.

Nesse contexto, o Partido dos Trabalhadores (PT), que havia disputado o segundo turno eleitoral, articula-se como governo paralelo e apresenta um documento (1991) 24, localizando a fome como questão central, consequência do modelo econômico adotado. Apresenta propostas para as políticas agrária e agrícola e uma política de segurança alimentar, em contraposição a programas compensatórios para combater a fome 24 . 
Quadro 1

Contexto, usos e sentidos da fome no debate político brasileiro (1986-2015).

\begin{tabular}{|c|c|c|c|}
\hline PERÍODO & CONTEXTO & DOCUMENTOS-CHAVE DA ÁREA & USOS E SENTIDOS DA FOME * \\
\hline \multirow[t]{5}{*}{$\begin{array}{l}\text { 1986-1994 - a entrada da } \\
\text { fome no debate político }\end{array}$} & $\begin{array}{c}\text { Brasil - início da década de } \\
1980 \text { - 8ạ economia mundial, 4oo } \\
\text { exportador mundial de alimentos, } \\
\text { 6o país em subnutrição. }\end{array}$ & $\begin{array}{c}\text { Relatório final da I CNAN (1986) } \\
\text { • Desdobramento da VIII CNS; } \\
\text { • Organizada pelo INAN/Ministério } \\
\text { Saúde; } \\
\text { • Objetiva subsidiar debate } \\
\text { constituinte; } \\
\text { - Propõe criação de um Conselho } \\
\text { e de um Sistema de Segurança } \\
\text { Alimentar e Nutricional. }\end{array}$ & $\begin{array}{l}\text { Na I CNAN a fome é trazida como } \\
\text { pauta política importante, mantendo } \\
\text { a ênfase nas carências nutricionais. } \\
\text { Introduz a ideia de segurança } \\
\text { alimentar e nutricional no debate da } \\
\text { área. } \\
\text { Mas a fome não é acionada } \\
\text { retoricamente no debate político. }\end{array}$ \\
\hline & $\begin{array}{l}\text { Governo da Nova República } \\
\text { - Presidente José Sarney (1985- } \\
\text { 1989) } \\
\text { • Economia instável e sucessivos } \\
\text { planos de estabilização. } \\
\text { - Pressão política e social para } \\
\text { concretização de uma nova } \\
\text { Constituição Federal (1988). }\end{array}$ & $\begin{array}{c}\text { Sem medo de trabalhar na terra - } \\
\text { Governo Paralelo PT ** (1991) } \\
\text { • Propostas para política agrícola e } \\
\text { política agrária; } \\
\text { - Proposta de criação de uma } \\
\text { política de segurança alimentar e } \\
\text { nutricional . }\end{array}$ & $\begin{array}{c}\text { No documento do governo paralelo, } \\
\text { a segurança alimentar e nutricional } \\
\text { aparece como prioridade na luta } \\
\text { contra a fome. A fome ganha força } \\
\text { retórica e está diretamente associada } \\
\text { à condição de miséria e como } \\
\text { consequência do modelo político e } \\
\text { econômico adotado pelos governos. }\end{array}$ \\
\hline & $\begin{array}{l}\text { Governo eleito de forma direta } \\
\text { - Presidente Fernando Collor } \\
\text { (1990-1992) } \\
\text { - Congelamento de preços e } \\
\text { confisco da poupança; adoção de } \\
\text { medidas de ajuste neoliberais, } \\
\text { com privatização de companhias } \\
\text { estatais e redução do papel do } \\
\text { Estado. } \\
\text { - Articulação social e política do } \\
\text { governo paralelo do PT. } \\
\text { - Impeachment do presidente } \\
\text { Collor. }\end{array}$ & $\begin{array}{l}\text { Relatório CPI da Fome (1991) - } \\
\text { Congresso Nacional } \\
\text { • Investigação das causas da fome } \\
\text { no Brasil; } \\
\text { • Comissão instalada no período de } \\
\text { impeachment. }\end{array}$ & $\begin{array}{l}\text { Na CPI a fome é apresentada como } \\
\text { um problema político. Reforça crítica } \\
\text { ao modelo político e econômico. }\end{array}$ \\
\hline & $\begin{array}{l}\text { Governo vice-presidente Itamar } \\
\text { Franco (1993-1994) } \\
\text { - Campanha da Ação da Cidadania } \\
\text { Contra a Fome, a Miséria e pela } \\
\text { Vida - protagonismo de Herbert } \\
\text { de Souza (Betinho). } \\
\text { • Criação do Consea (1993). }\end{array}$ & \begin{tabular}{|} 
O Mapa da Fome (1991) \\
- Produzido pelo Ipea por solicitação \\
de Betinho, como estratégia para \\
mobilização política e social; \\
• Contabilizou 32 milhões de \\
pessoas vivendo abaixo da pobreza.
\end{tabular} & $\begin{array}{l}\text { No Mapa os conceitos de fome, } \\
\text { miséria, indigência e pobreza se } \\
\text { misturam e a metodologia de cálculo } \\
\text { da pobreza sofreu críticas pela falta } \\
\text { de rigor. }\end{array}$ \\
\hline & & \begin{tabular}{|} 
Relatório final da I CNSA (1994) - \\
“Fome, a questão nacional” \\
• Organizada pelo Consea e \\
realizada em parceria com a Ação da \\
Cidadania; \\
- Apresenta-se como uma pauta \\
política para os candidatos à \\
Presidência; \\
- Segurança alimentar e nutricional \\
como estratégia no combate à fome.
\end{tabular} & $\begin{array}{l}\text { A fome é acionada retoricamente na } \\
\text { crítica ao modelo de desenvolvimento } \\
\text { que produz concentração de renda e } \\
\text { desigualdade. Sustenta novo projeto } \\
\text { de desenvolvimento nacional, que } \\
\text { tem como "componente estratégico" } \\
\text { a política de segurança alimentar e } \\
\text { nutricional. }\end{array}$ \\
\hline
\end{tabular}

(continua) 


\begin{tabular}{|c|c|c|c|}
\hline PERÍODO & CONTEXTO & DOCUMENTOS-CHAVE DA ÁREA & USOS E SENTIDOS DA FOME * \\
\hline \multirow[t]{5}{*}{$\begin{array}{l}\text { 1995-2002 - a fome na disputa } \\
\text { política }\end{array}$} & $\begin{array}{c}\text { Brasil (1994) - 2a disputa } \\
\text { eleitoral pós redemocratização } \\
\text { - 1ạ disputa eleitoral FHC/PSDB- } \\
\text { Lula/PT } \\
\text { • Estabilização da moeda com o } \\
\text { Plano Real (1994) e controle da } \\
\text { inflação - Ministro da Fazenda } \\
\text { FHC. } \\
\text { - Dois candidatos em destaque: } \\
\text { FHC (PSDB) e Lula (PT). }\end{array}$ & $\begin{array}{c}\text { Mãos à obra Brasil (1994) - } \\
\text { Programa de Campanha FHC } \\
\text { - Estratégia desenvolvimentista com } \\
\text { ênfase no crescimento econômico; } \\
\text { - Ênfase em programas assistenciais } \\
\text { e compensatórios. }\end{array}$ & $\begin{array}{l}\text { A fome não é um tema de destaque } \\
\text { no Programa e a política de } \\
\text { segurança alimentar e nutricional não } \\
\text { é incorporada. }\end{array}$ \\
\hline & $\begin{array}{c}\text { Governo FHC (1995-2002) } \\
\text { • Avanço do liberalismo } \\
\text { econômico, ajuste estrutural com } \\
\text { abertura externa da economia e } \\
\text { elevação da taxa de juros. } \\
\text { • Fortalecimento do terceiro setor. } \\
\text { • Precarização de vínculos } \\
\text { trabalhistas. } \\
\text { • Extinção do Consea (1995). } \\
\text { • Criação do Conselho da } \\
\text { Comunidade Solidária (1995) } \\
\text { e definição do Programa } \\
\text { Comunidade Solidária (1996). } \\
\text { • Extinção do Instituto Nacional de } \\
\text { Alimentação e Nutrição e criação } \\
\text { de uma área técnica no Ministério } \\
\text { da Saúde (1997). } \\
\text { • Política Nacional de Alimentação } \\
\text { e Nutrição (1999). } \\
\text { • Projeto Alvorada (2001) e } \\
\text { Programas de transferência } \\
\text { de renda - Bolsa-Escola, Bolsa- } \\
\text { Alimentação e Auxílio-Gás (2001). }\end{array}$ & $\begin{array}{l}\text { Uma revolução democrática } \\
\text { no Brasil (1994) Programa de } \\
\text { Campanha Lula } \\
\text { • Estratégia desenvolvimentista } \\
\text { com ênfase no enfrentamento das } \\
\text { desigualdades sociais; } \\
\text { • Objetivo central: combater a } \\
\text { pobreza e a indigência, acabar com } \\
\text { a fome. } \\
\end{array}$ & $\begin{array}{l}\text { A fome é acionada como tema } \\
\text { central do debate político e seu } \\
\text { enfrentamento é componente } \\
\text { estratégico para um novo ciclo de } \\
\text { desenvolvimento. }\end{array}$ \\
\hline & $\begin{array}{c}\text { Brasil - } 2002 \text { - 2a disputa } \\
\text { eleitoral FHC/PSDB-Lula/PT } \\
\text { • Economia estabilizada e em } \\
\text { crescimento. } \\
\text { - Desigualdades acentuadas. }\end{array}$ & $\begin{array}{c}\text { Uma estratégia de } \\
\text { desenvolvimento social - FHC } \\
\text { (1996) } \\
\text { - Atualiza programa de governo e } \\
\text { reafirma estratégia de crescimento } \\
\text { e ajuste; } \\
\text { - Define o Programa Comunidade } \\
\text { Solidária como estratégia para a } \\
\text { definição de ações sociais. }\end{array}$ & $\begin{array}{l}\text { A fome perde centralidade e é } \\
\text { esvaziada no debate político. }\end{array}$ \\
\hline & & $\begin{array}{l}\text { Comunidade Solidária - Todos por } \\
\text { Todos (1996) } \\
\text { • Enfrentamento da pobreza por } \\
\text { meio da participação social; } \\
\text { - Ações de caráter assistencialista. }\end{array}$ & $\begin{array}{l}\text { A fome não é acionada e a questão é } \\
\text { tratada tecnicamente. }\end{array}$ \\
\hline & & $\begin{array}{l}\text { Avança Brasil - FHC (1998) } \\
\text { • Resgate da dívida social; } \\
\text { • Transferência de renda e } \\
\text { programas/medidas para acabar } \\
\text { com a fome e a miséria. }\end{array}$ & $\begin{array}{l}\text { A fome é abordada como resultado } \\
\text { de uma pressão política e social. }\end{array}$ \\
\hline
\end{tabular}


Quadro 1 (continuação)

\begin{tabular}{|c|c|c|c|}
\hline PERÍODO & CONTEXTO & DOCUMENTOS-CHAVE DA ÁREA & USOS E SENTIDOS DA FOME * \\
\hline \multirow[t]{3}{*}{$\begin{array}{l}\text { 1995-2002 - a fome na disputa } \\
\text { política }\end{array}$} & & \begin{tabular}{|c|} 
União do povo - Muda Brasil - \\
Lula (1998) \\
• Compromissos afirmados \\
sinalizando inclusão e redistribuição \\
social e estabilização econômica.
\end{tabular} & $\begin{array}{l}\text { A fome ganha expressão retórica } \\
\text { e vem articulada ao debate sobre } \\
\text { o projeto de desenvolvimento com } \\
\text { redistribuição. }\end{array}$ \\
\hline & & $\begin{array}{l}\text { Política Nacional de Alimentação } \\
\text { e Nutrição - PNAN (1999) } \\
\text { • mudanças no perfil alimentar e } \\
\text { nutricional da população; } \\
\text { • incorporação do conceito de } \\
\text { segurança alimentar e nutricional e } \\
\text { de DHAA. }\end{array}$ & $\begin{array}{l}\text { A PNAN não traz a fome como } \\
\text { questão central e adota uma diretriz } \\
\text { mais técnica no monitoramento pela } \\
\text { vigilância. }\end{array}$ \\
\hline & & $\begin{array}{l}\text { Programa de Governo Lula (2002) } \\
\text { • combate à inflação e geração de } \\
\text { empregos; } \\
\text { • combate à fome. }\end{array}$ & $\begin{array}{l}\text { A fome é usada de forma retórica } \\
\text { - “quem tem fome tem pressa” - } \\
\text { para ser combatida com a política } \\
\text { econômica articulada com a política } \\
\text { social. A estratégia tem a reforma } \\
\text { agrária como pauta importante para } \\
\text { o alcance de segurança alimentar e } \\
\text { nutricional. }\end{array}$ \\
\hline $\begin{array}{l}2003-2010 \text { - a fome como } \\
\text { prioridade de governo }\end{array}$ & $\begin{array}{c}\text { Governo Lula (2003-2010) } \\
\text { • Coalizão governista. } \\
\text { • Crescimento acelerado, } \\
\text { expansão do mercado interno, } \\
\text { desenvolvimento econômico e } \\
\text { mobilidade social. } \\
\text { • Redução da pobreza e extrema } \\
\text { pobreza. } \\
\text { • Aumento do poder de compra. } \\
\text { • Expansão de direitos de grupos } \\
\text { socialmente vulneráveis. } \\
\text { • Criação do Ministério } \\
\text { Extraordinário de Combate } \\
\text { à Fome, com o objetivo de } \\
\text { implementar o Programa Fome } \\
\text { Zero (2003). } \\
\text { • Recriação do Consea (2003). } \\
\text { • Extinção do Ministério } \\
\text { Extraordinário de Combate à } \\
\text { Fome e criação do Ministério } \\
\text { de Desenvolvimento social e } \\
\text { Combate à Fome, e implantação } \\
\text { do Programa Bolsa Família (2004). } \\
\text { • Criação do Sisan (2006). } \\
\text { • Sancionada a Lei Orgânica de } \\
\text { Segurança Alimentar e Nutricional } \\
\text { (Losan) (2006). } \\
\text { • Publicação da PNSAN (Decreto no } \\
\text { • Promulgação da Emenda } \\
\text { Constitucional no 64/2010. }\end{array}$ & \begin{tabular}{|c|} 
Projeto Fome Zero (2003) \\
- Novo modelo de desenvolvimento \\
- investir na área social de forma \\
atrelada com a econômica; \\
- Medidas emergenciais e estruturais \\
para combater a fome; \\
- Incentivo à mobilização social.
\end{tabular} & $\begin{array}{l}\text { Combate à fome como um } \\
\text { investimento - aumento do consumo } \\
\text { - produção-empregos. } \\
\text { Articulado com o debate de } \\
\text { segurança alimentar e nutricional. }\end{array}$ \\
\hline
\end{tabular}

(continua) 
Quadro 1 (continuação)

\begin{tabular}{|c|c|c|c|}
\hline PERÍODO & CONTEXTO & DOCUMENTOS-CHAVE DA ÁREA & USOS E SENTIDOS DA FOME * \\
\hline \multirow[t]{5}{*}{$\begin{array}{l}2003-2010 \text { - a fome como } \\
\text { prioridade de governo }\end{array}$} & & \begin{tabular}{|c|} 
Relatório II CNSAN (2004) \\
- Reafirma conceito de segurança \\
alimentar e nutricional e introduz \\
o conceito de insegurança alimentar; \\
• Propõe instituir um Sistema \\
Nacional de Segurança Alimentar e \\
Nutricional Sustentável.
\end{tabular} & $\begin{array}{l}\text { A fome se insere em um espaço mais } \\
\text { amplo de debate sobre segurança } \\
\text { alimentar e nutricional, DHAA, } \\
\text { Soberania Alimentar. Não se usa mais } \\
\text { a fome retoricamente. } \\
\text { Aparece a ideia de insegurança } \\
\text { alimentar para retratar tanto a fome e } \\
\text { a desnutrição quanto a obesidade. }\end{array}$ \\
\hline & & $\begin{array}{c}\text { Programa de Governo Lula (2006) } \\
\text { - Continuidade do governo e dos } \\
\text { programas sociais. }\end{array}$ & $\begin{array}{c}\text { Não se fala em número de famintos; } \\
\text { a retórica da fome não é acionada. } \\
\text { Mantém as medidas emergenciais e } \\
\text { estruturais. }\end{array}$ \\
\hline & & $\begin{array}{c}\text { Relatório III CNSAN (2007) } \\
\text { - Crítica ao governo - agronegócio x } \\
\text { agroecologia; } \\
\text { - Diretrizes para mudanças } \\
\text { estruturais - Reforma Agrária. }\end{array}$ & $\begin{array}{c}\text { Fome como insegurança alimentar } \\
\text { grave. }\end{array}$ \\
\hline & & $\begin{array}{c}\text { Bolsa Família - "Cidadania e } \\
\text { dignidade para milhões de } \\
\text { brasileiros" (2010) } \\
\text { • Mostra o impacto do Programa na } \\
\text { melhoria das condições de vida. }\end{array}$ & $\begin{array}{l}\text { Fome como consequência do modelo } \\
\text { de desenvolvimento hegemônico. }\end{array}$ \\
\hline & & & $\begin{array}{c}\begin{array}{c}\text { Não usa a fome de forma retórica; } \\
\text { mostra os impactos a partir de relatos } \\
\text { e não de números. }\end{array} \\
\end{array}$ \\
\hline \multirow[t]{2}{*}{$\begin{array}{l}\text { 2011-2015 - a fome sai do } \\
\text { debate }\end{array}$} & $\begin{array}{c}\text { Governo Dilma Rousseff (10 } \\
\text { mandato - 2011-2014) e 20 } \\
\text { mandato - 2015) } \\
\text { - Cenário econômico e social } \\
\text { estável. } \\
\text { - Desenho de novas estratégias } \\
\text { desenvolvimentistas. } \\
\text { - Plano Brasil sem Miséria. } \\
\text { - Brasil sai do Mapa da Fome } \\
\text { Mundial da ONU em 2014. } \\
\text { - Impeachment em agosto de } \\
2016 .\end{array}$ & $\begin{array}{c}\text { IV CNSAN - Alimentação } \\
\text { adequada e saudável - direito de } \\
\text { todos (2011) } \\
\text { - Objetiva construir compromissos } \\
\text { para efetivar o direito humano à } \\
\text { alimentação adequada e saudável } \\
\text { e promover a soberania alimentar - } \\
\text { subsidiar PNAN e Sisan. }\end{array}$ & $\begin{array}{l}\text { Soberania e segurança alimentar e } \\
\text { nutricional como eixo estratégico do } \\
\text { desenvolvimento socioeconômico } \\
\text { - condição para erradicar a fome. } \\
\text { O foco é segurança alimentar e } \\
\text { nutricional. }\end{array}$ \\
\hline & & $\begin{array}{c}\text { PNAN (2013) } \\
\text { • Revisa PNAN 1999; } \\
\text { • Tem como propósito melhorar as } \\
\text { condições de alimentação, nutrição } \\
\text { e saúde, em busca da garantia da } \\
\text { segurança alimentar e nutricional da } \\
\text { população brasileira. }\end{array}$ & $\begin{array}{l}\text { O foco é segurança alimentar } \\
\text { e nutricional e as situações de } \\
\text { insegurança abarcam novos } \\
\text { problemas como a obesidade. }\end{array}$ \\
\hline
\end{tabular}

(continua) 
Quadro 1 (continuação)

\begin{tabular}{|c|c|c|c|}
\hline PERÍODO & CONTEXTO & DOCUMENTOS-CHAVE DA ÁREA & USOS E SENTIDOS DA FOME * \\
\hline \multirow[t]{2}{*}{$\begin{array}{l}2011-2015 \text { - a fome sai do } \\
\text { debate }\end{array}$} & & $\begin{array}{l}\text { Plano Brasil sem Miséria - Ficha- } \\
\text { resumo (2011) e Caderno de } \\
\text { Resultados (2015) } \\
\text { - Visa superar a extrema pobreza. } \\
\text { - Define três eixos estratégicos: } \\
\text { (1) garantia de renda, para alívio } \\
\text { imediato da situação de pobreza; } \\
\text { (2) acesso a serviços públicos; e (3) } \\
\text { inclusão produtiva. }\end{array}$ & $\begin{array}{c}\text { A fome não é acionada retoricamente. } \\
\text { O foco é o combate à extrema } \\
\text { pobreza. A segurança alimentar } \\
\text { e nutricional compõe a estratégia } \\
\text { juntamente com outras áreas e } \\
\text { políticas. }\end{array}$ \\
\hline & & $\begin{array}{c}\text { V CNSAN (2015) } \\
\text { • Ampliar e fortalecer os } \\
\text { compromissos com a soberania } \\
\text { alimentar e DHAA. }\end{array}$ & $\begin{array}{l}\text { A ênfase é segurança alimentar e } \\
\text { nutricional e soberania alimentar, } \\
\text { mas recorre-se à fome na discussão } \\
\text { da agroecologia e na indicação dos } \\
\text { grupos vulneráveis. }\end{array}$ \\
\hline
\end{tabular}

CNAN: Conferência Nacional de Alimentação e Nutrição; CNS: Conselho Nacional de Saúde; CNSA: Conferência Nacional de Segurança Alimentar; CNSAN: Conferência Nacional de Segurança Alimentar e Nutricional; Consea: Conselho Nacional de Segurança Alimentar e Nutricional; CPI: Comissão Parlamentar de Inquérito; DHAA: direito humanos à alimentação adequada; FHC: Fernando Henrique Cardoso; INAN: Instituto Nacional de Alimentação e Nutrição; IPEA: Instituto de Pesquisa Econômica Aplicada; ONU: Organização das Nações Unidas; PNAN: Política Nacional de Alimentação e Nutrição; PSDB: Partido da Social Democracia Brasileira; PT: Partido dos Trabalhadores; Sisan: Sistema Nacional de Segurança Alimentar e Nutricional. Fonte: Elaboração das autoras a partir dos documentos.

* Na leitura dos documentos, foram localizadas as palavras "fome" e "segurança alimentar", bem como as palavras semelhantes (famintos, famélicos, insegurança alimentar, Consea, sistemas de segurança alimentar, Política Nacional de Segurança Alimentar, segurança alimentar e nutricional).

** O Governo Paralelo foi constituído em 1990 como instrumento de ação política para uma oposição qualificada ao governo Collor, buscando exercer uma fiscalização democrática.

No Legislativo, inicia-se uma CPI (1991) destinada a "apurar as causas e os responsáveis pela fome no Brasil e a iminente ameaça à segurança alimentar” 25 (p. 1). A CPI relaciona a fome à miséria e enfatiza que sua principal causa é a má distribuição de renda, acentuada pelas políticas recessivas dos anos anteriores. Faz uma crítica à intervenção governamental por programas compensatórios e aposta em outro modelo produtivo e distributivo como solução para o problema da fome no país.

A CPI 25 e a proposta do governo paralelo 24 sinalizam para: mudanças no modelo econômico; urgência da reforma agrária e agrícola; apoio aos pequenos e médios produtores rurais; e importância de subsídios governamentais para alimentos da cesta básica. A temática da fome se apresentava de forma mais contundente no debate político, porém fora da agenda governamental.

Com o impeachment do presidente (1992), configura-se uma nova coalizão política e abertura para diálogo, sem uma mudança na direção neoliberal da economia 9 . Ante o cenário de precariedade social, ganha expressão o movimento Ação da Cidadania Contra a Fome, a Miséria e pela Vida, liderado por Herbert de Souza (Betinho) 23, reforçado pela divulgação do Mapa da Fome 10, contabilizando 32 milhões de brasileiros abaixo da linha da pobreza.

Com a expressão "quem tem fome, tem pressa" 26 (p. 167). Betinho mobilizava a sociedade para a doação de alimentos e intensificava o debate sobre a fome ${ }^{27}$. O movimento tencionava a ação do Estado, mas também atendia à perspectiva neoliberal de estímulo à atuação da sociedade para enfrentamento de seus problemas.

Em 1993, o governo cria o Conselho Nacional de Segurança Alimentar e Nutricional (Consea) e realiza, em 1994, a I Conferência Nacional de Segurança Alimentar (I CNSA), em parceria com a Ação da Cidadania, trazendo a fome como tema central 28. A conferência gera uma carta-compromisso a ser entregue aos candidatos à Presidência e o Mapa da Fome é utilizado para sustentar um novo projeto de desenvolvimento nacional, cujo componente estratégico 28 era a política de segurança alimentar. 


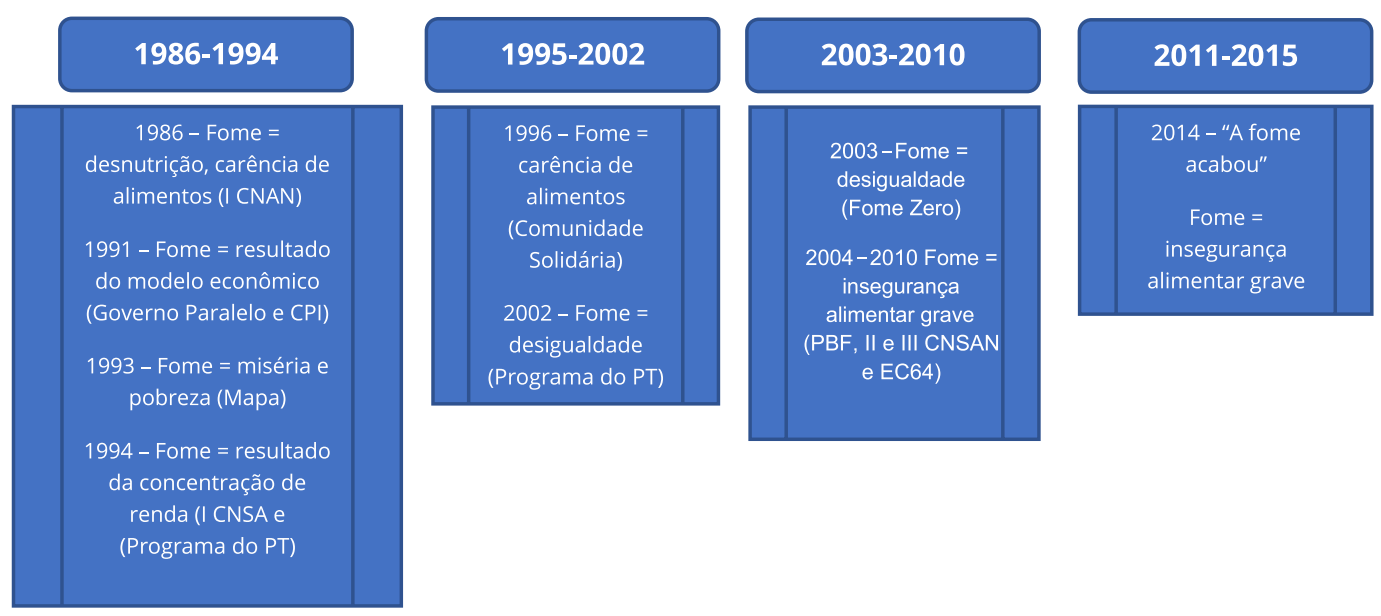

CNAN: Conferência Nacional de Alimentação e Nutrição; CNSA: Conferência Nacional de Segurança Alimentar; CNSAN: Conferência Nacional de Segurança Alimentar e Nutricional; CPI: Comissão Parlamentar de Inquérito; EC64: Emenda Constitucional no 64/2010; PBF: Programa Bolsa Família;

PT: Partido dos Trabalhadores.

\section{A fome na disputa política (1995-2002)}

Mil novecentos e noventa e quatro é um ano de disputa eleitoral e a fome permeia o debate dos candidatos favoritos: Fernando Henrique Cardoso (FHC), pelo Partido da Social Democracia Brasileira (PSDB); e Luís Inácio Lula da Silva, pelo PT.

A proposta de FHC centrava-se numa aposta desenvolvimentista que assumia o crescimento econômico como condição para erradicação da miséria e da pobreza 29 . Para o enfrentamento da fome, distanciava-se da linha proposta pelo Consea e trazia como estratégia a modernização agrícola e a produção em grande escala, focando o acesso ao alimento 29 e sinalizando também para manutenção da lógica assistencialista na distribuição de alimentos.

O programa de Lula também trazia a pauta desenvolvimentista, contudo selava o compromisso de enfrentamento das desigualdades sociais 30, tendo como meta central "combater a pobreza e a indigência" 31 (p. 4) e "acabar com a fome" 31 (p. 11). Na direção oposta a FHC, reforçava a necessidade de uma política de segurança alimentar, seguindo o direcionamento do Consea, retomando também o argumento da urgência dos 32 milhões de famintos 10.

$\mathrm{Na}$ disputa entre os projetos, ganhou a retórica da estabilidade econômica de FHC, que manteve uma política de ajuste com enxugamento do Estado 9 . Quanto às políticas de combate à fome e de alimentação e nutrição, suas estratégias foram: a extinção do Consea, a criação do Programa Comunidade Solidária (1995) e a extinção do Instituto Nacional de Alimentação e Nutrição (1997) 32, com a criação da área técnica no Ministério da Saúde.

O Comunidade Solidária materializa-se 33 num contexto de críticas em relação ao rumo das políticas sociais 34 . Define-se como a principal estratégia de política social no combate à fome, contando com a ajuda de algumas ONGs e reproduzindo a lógica das campanhas comunitárias e assistenciais na distribuição de alimentos.

Fora do aparato estatal, o debate sobre fome, alimentação e nutrição se atualiza na mobilização daqueles que haviam iniciado, no âmbito do extinto Consea, o desenho de uma política de segurança alimentar e nutricional, preparando-se para o debate na Cúpula Mundial de Alimentação de 199635. 
A mobilização levou à criação, em 1998, do Fórum Brasileiro de Soberania e Segurança Alimentar e Nutricional (FBSSAN), inaugurando um espaço permanente de debate e proposições em prol da segurança alimentar e nutricional, mantendo viva a discussão e fortalecendo a implementação de Consea estaduais 35 .

A despeito da orientação política do governo, a área técnica de alimentação e nutrição do Ministério da Saúde logrou avançar em direção à segurança alimentar e nutricional, como na Política Nacional de Alimentação e Nutrição (PNAN), documento técnico referido à vigilância alimentar e nutricional que incorporou os conceitos de segurança alimentar e nutricional e de direito humano à alimentação adequada (DHAA), sinalizando uma interface com outros setores e áreas do governo 32 .

Um segundo processo eleitoral envolvendo FHC e Lula (1998) trouxe novamente para centralidade a situação da fome no país. FHC reconheceu a situação de miséria e fome, mantendo a diretriz de parceria com a sociedade e estabilização econômica para realização de políticas mais distributivas 36. Outra vez não se comprometeu com as pautas de segurança alimentar e nutricional, mantendo a orientação das políticas agrária e agrícola. Lula retomou a linha argumentativa das últimas campanhas e organizou seu programa 37,38,39 em torno da ideia de crescimento com distribuição de renda, assumindo o enfrentamento da fome como uma de suas prioridades, tendo como base a política de segurança alimentar e nutricional e a recriação do Consea.

Novamente venceu o projeto FHC. No novo mandato, a política social sofreu reestruturações, com estratégias mais abrangentes para enfrentamento da miséria e da pobreza, mas ainda sem enfrentar questões estruturais. Foram extintos os programas com ênfase assistencialista (distribuição de alimentos) e adotados projetos com a perspectiva de desenvolvimento local integrado e sustentável (DLIS), englobando programas de transferência de renda, como o Bolsa-Escola, Bolsa-Alimentação e Auxílio-Gás 40,41,42.

Ainda assim, persistiam as desigualdades e em 2001 a fome novamente é acionada no debate político, coincidindo com a proximidade da eleição presidencial (2002) e a visita ao país do representante do direito à alimentação da Comissão de Direitos Humanos da ONU 43.

Lula inicia nova mobilização política, retomando a retórica da fome e da miséria - "a fome não espera e segue matando a cada dia” 44 (p. 43) - e apresentando novamente a proposta de segurança alimentar e nutricional 11, conectada ao debate da reforma agrária, mas dessa vez dando lugar a propostas reformistas moderadas e conciliadoras 44,45 .

As eleições foram marcadas pela forte retórica da fome, pobreza e desigualdades denunciadas pelo PT, com esvaziamento das propostas do candidato governista. O resultado foi a vitória do PT, após quatro processos eleitorais como partido de oposição ao governo 42.

\section{A fome como prioridade de governo (2003-2010)}

Na posse, Lula reafirmou seu incômodo com a permanência da fome: "se, ao final do meu mandato, todos os brasileiros tiverem a possibilidade de tomar café da manhã, almoçar e jantar, terei cumprido a missão da minha vida" 46 (p. 4). Convocou o povo para um mutirão nacional e definiu como prioridade o Programa Fome Zero 11,47.

O Programa Fome Zero destinava-se a 44 milhões de pessoas consideradas muito pobres, por ganharem menos de um dólar por dia (o que equivalia a R \$ 80,00/mês). Com o título Para Acabar com a Fome, introduz a questão da alimentação de qualidade, definida como "direito inalienável de todo cidadão, sendo dever do Estado criar as condições para que a população brasileira possa efetivamente usufruir dele" 11 (p. 6). Associada à retórica da fome estava a de segurança alimentar e nutricional.

O eixo do Programa Fome Zero estava na conjugação de políticas estruturais (redistribuição da renda, crescimento da produção, geração de empregos, reforma agrária) e emergenciais, apontando para a construção de "um novo Brasil" 11 (p. 7).

A fome é apresentada como produto da pobreza e da falta de recurso para obter o alimento, ressaltando as diferenças no campo e na cidade 11 , o que exigiria políticas públicas específicas para as duas realidades. A ênfase estava no consumo e não na qualidade do alimento, apesar de partir-se da perspectiva de segurança alimentar e nutricional. 
Para implementar o Programa Fome Zero, cria-se o Ministério Extraordinário de Combate à Fome e (re)cria-se o Consea 35,48. Inicia-se uma mobilização política em torno do Programa Fome Zero 49, com incentivo para que estados e municípios formassem conselhos, visando aumentar a participação e o controle social 50,51.

Mas em 2004, o Ministério Extraordinário de Combate à Fome é extinto e sua estrutura incorporada ao novo Ministério do Desenvolvimento Social e Combate à Fome. A nova estrutura marcou o lançamento do Programa Bolsa Família, fruto da unificação dos programas Bolsa-Escola, Bolsa-Alimentação, Auxílio-Gás e Cartão Alimentação 42.

Passam a conviver e disputar no governo duas estratégias e perspectivas distintas no combate à fome: Programa Fome Zero e Programa Bolsa Família. O Programa Fome Zero tinha como objetivo a constituição de uma política intersetorial/interministerial e participativa, com a mobilização de toda sociedade no combate à fome. Exigia um esforço de articulação e um modo de operar próximo a política do âmbito local. O Programa Bolsa Família partia de um desenho de política já institucionalizado e com mecanismos de controle estabelecidos na relação com os entes federativos, tomando como base as experiências acumuladas nos programas de transferência de renda, tendo como foco o combate à pobreza e estabelecendo condicionalidades para recebimento do benefício, como o acompanhamento do desenvolvimento das crianças pelas equipes de saúde.

No final de 2004, o Programa Bolsa Família firma-se como projeto político mais capitalizável e viável 47, e o Programa Fome Zero desaparece paulatinamente. Juntamente com a afirmação do Programa Bolsa Família, ocorre o fortalecimento da política de segurança alimentar e nutricional 47 , reivindicando uma mudança estrutural para garantia do acesso ao alimento de qualidade e em quantidade suficiente, de forma permanente, com ações no âmbito da agricultura e produção do alimento 52 e com a promoção da alimentação adequada e saudável. Assim, de 2003 a 2010, importantes conquistas foram obtidas: a promulgação da Lei Orgânica de Segurança Alimentar e Nutricional (Losan) a criação do Sistema Nacional de Segurança Alimentar e Nutricional (Sisan) e da Política Nacional de Segurança Alimentar e Nutricional (PNSAN) 53, com a sustentação da ideia de soberania alimentar e DHAA 54, e a aprovação da Emenda Constitucional (EC) no 64/2010, que incluiu a alimentação como direito social 55

Com o desenvolvimento das políticas sociais, a retórica da fome não é mais mobilizada nas campanhas presidenciais de 2006 e 2010. A política de combate à fome se materializa com o desenvolvimento da segurança alimentar e nutricional. Em vez de fome, introduz-se a concepção de insegurança alimentar grave, a partir do uso da EBIA. Com essa escala, a fome passa a ser considerada a partir da percepção das pessoas do não acesso ao alimento pela falta de renda, uma abordagem distinta dos indicadores de pobreza e indigência. Também, o termo insegurança alimentar passa a ser usado para identificar outras situações decorrentes da alimentação inadequada, como obesidade, desnutrição e qualidade do alimento, tornando a questão mais complexa e abrangente.

Nas II e III Conferências de Segurança Alimentar e Nutricional, de 2004 e 2007, a insegurança alimentar grave (fome) não é tema de debate. Os temas centrais são as mudanças no consumo alimentar da população e o uso de agrotóxicos e transgênicos na produção de alimentos, com implicações em especial para grupos específicos e constantemente vulnerabilizados 52,53,54,55,56.

Em 2010, é publicado um balanço do Programa Bolsa Família 57. O documento constrói, a partir de relatos de beneficiários, uma nova retórica: a de que "a fome acabou". Diferentemente de outros momentos do debate político sobre a fome, não foram acionados dados ou levantamentos de famintos.

O debate volta-se para a pobreza e a necessidade de definição de políticas estruturais que garantissem uma mudança na reprodução social das desigualdades. Tratava-se de responder às críticas sobre a condução de uma política compensatória, como havia sido o Programa Fome Zero e a exaltação ao modelo adotado pelo Programa Bolsa Família, sem colocar este em análise. 


\section{A fome sai do debate (2011-2015)}

O cenário econômico e social em 2011 era bastante favorável. Apesar da crise econômica mundial de 2008, o país havia mantido razoáveis índices de desenvolvimento econômico e mobilidade social, combinando políticas neoliberais para conter a inflação com políticas redistributivas 30 . Os efeitos da crise se fariam sentir no final do primeiro mandato da presidenta Dilma Rousseff (2014), mas até lá foi possível iniciar uma nova estratégia desenvolvimentista com enfrentamento das desigualdades sociais.

O Programa Bolsa Família continuou sendo uma estratégia central do governo e a partir de 2013 as políticas de combate à pobreza e miséria ganharam reforço com o Plano Brasil sem Miséria 58,59 assumindo como foco a superação da extrema pobreza. As ações previstas no Brasil sem Miséria visavam construir um caminho de mudança, traçando uma rota desenvolvimentista e tendo como eixos a garantia de renda, o acesso a serviços públicos e a inclusão produtiva.

Em 2014, o país conquistava a vitória de sair do Mapa da Fome da ONU (com menos de 5\% em situação de subalimentação). A experiência brasileira torna-se uma referência internacional e a retórica da fome cai em desuso no debate político. Direciona-se a discussão para a pobreza, miséria e outras situações de insegurança alimentar, como a obesidade e a qualidade do alimento consumido, conforme enfatizado na PNAN 201360 e nas IV CNSAN 61 e V CNSAN 62.

A mudança na retórica política reflete um momento de conquista de melhores indicadores sociais e de afirmação da condução adotada desde o início do governo Lula. Contudo, no que tange ao uso retórico de insegurança alimentar em substituição ao uso de fome, há implicações políticas e sociais importantes que merecem ser observadas. Primeiro: o conceito de insegurança alimentar engloba diversos e diferentes problemas alimentares - fome, obesidade, desnutrição, uso de transgênicos e agrotóxicos -, e ao assumi-lo pode-se gerar um efeito de apagamento da situação real de fome que atinge grupos específicos. Segundo: a metodologia adotada pelo Instituto Brasileiro de Geografia e Estatística (IBGE) para identificar as situações de insegurança alimentar baseia-se na amostra de domicílios particulares, não abrangendo os grupos mais vulneráveis à fome, como a população em situação de rua, indígenas, quilombolas e outros 63 . Portanto, presume-se que o quantitativo de pessoas em situação de insegurança alimentar seja subestimado.

Sustentar em 2014 uma retórica positiva no combate à fome era uma questão importante e estratégica: o cenário era de nova disputa eleitoral. Mas não assumir a persistência da fome também foi um uso político com consequências para a população e para a institucionalidade da própria política de segurança alimentar e nutricional.

Dilma Rousseff foi reeleita, mas a partir de 2015 a situação política e econômica começou a se agravar. Há aumento do desemprego, congelamento de investimento social e baixa governabilidade. Em dezembro de 2015, inicia-se um processo de impeachment da presidenta, que é destituída em agosto de 2016. Após esse período, o governo avançou pouco nos projetos previstos e gradativamente tomaram corpo no debate público as situações de fome ${ }^{12}$, agudizadas pelas políticas de ajuste adotadas 64 .

\section{Sobre os usos e sentidos da fome no debate político}

Ao acompanharmos a trajetória de 30 anos de debate político, observamos que a fome surgiu como retórica importante em momentos-chave da história brasileira, em especial para a crítica às ações de governo e como pressão social para mudanças nos rumos da política de Estado.

No primeiro momento (1986-1994), trazer a retórica da fome foi importante para mobilizar o debate político e social, sinalizando para problemas estruturais, mas a centralidade do debate ainda se restringia a melhorar o acesso ao alimento e combater as carências nutricionais 22,28 . O sentido da fome se aproximava de pobreza, inclusive a partir do uso de indicadores de pobreza para falar de fome.

O segundo momento (1995-2002) foi de enfrentamento mais explícito do projeto de Estado e da perspectiva de desenvolvimento, enfatizando as desigualdades como questão central. A fome é trazida por movimentos sociais e partidos políticos como denúncia de um modelo que reforçava a exclusão e a injustiça social. Assim, pensar uma política de segurança alimentar e nutricional se desenhou como uma resposta mais abrangente para enfrentamento de questões estruturais, pois se tratava de revisar 
as políticas agrárias e agrícolas em prol de um alimento de qualidade, garantindo também a soberania do país. Mas a construção de uma política de segurança alimentar e nutricional na esfera governamental ainda não era viável e o sentido de fome que predominava na arena governamental ainda era de acesso ao alimento.

Foi especialmente pela denúncia da fome e das persistentes desigualdades sociais que se alcançou no início da década de 2000 uma mudança de direcionalidade na política brasileira. O terceiro momento (2003-2010) inicia com a estratégia da fome como eixo central 42,43,44,45. A mobilização em torno do Programa Fome Zero foi a expressão primeira de uma política de combate imediato à fome, sendo substituída gradativamente por políticas redistributivas como o Programa Bolsa Família. Nesse contexto, se potencializou o desenvolvimento da política de segurança alimentar e nutricional, fundamentada na análise das relações econômicas, sociais e culturais que possibilitam o acesso ao alimento de qualidade, ampliando o debate para muito além da fome 47,52,56.

No quarto momento (2011-2015), a fome já não foi mais acionada no debate político. Ao contrário, o Brasil saíra do Mapa da Fome 1. O problema agora era a pobreza, as persistentes desigualdades e as situações diversas de insegurança alimentar. De fato, ocorrera uma mudança no padrão alimentar da população, com a ampliação do acesso ao alimento, decorrente do sucesso das políticas sociais e agrícolas, mas também havia um problema a ser enfrentado no modelo agrícola 62 , revelando as contradições de uma política que se associou ao agronegócio, com pautas e princípios totalmente contrários à segurança alimentar e nutricional.

A partir de 2016 a fome retorna ao debate social 12, num cenário de ajuste e crise. Inúmeras medidas atacam diretamente a soberania alimentar e o DHAA: aprovação da EC no 95/2016 64, congelando gastos públicos por 20 anos; desmontes de ministérios da área social; cortes em programas sociais - Programa de Aquisição de Alimentos da agricultura familiar, Programa um milhão de Cisternas, Programa Bolsa Família, Programa Cestas de Alimentos (para indígenas e quilombolas) -; desmonte da rede de equipamentos públicos de segurança alimentar e nutricional - restaurantes populares, bancos de alimentos e cozinhas comunitárias. Paralelamente, avançaram medidas que beneficiam o agronegócio e ameaçam propostas de reforma agrária, como o perdão a dívidas de produtores rurais e cortes nas ações orçamentárias referentes à política fundiária. Finalmente, como uma das primeiras medidas do governo Jair Bolsonaro, o Consea nacional foi extinto (2019), assim como vários outros conselhos de participação social 65 .

A extinção do Consea levou à desestruturação do Sisan e a não realização da VI CNSAN. A capacidade do Estado brasileiro de garantir o DHAA fica comprometida, demarcando-se a ruptura do diálogo desse governo com a sociedade civil. Como resposta, foram organizadas pela sociedade civil diversas mobilizações, como o Banquetaço Nacional (2019), que visou chamar atenção para as consequências dessa medida e a convocação da Conferência Popular de Soberania e Segurança Alimentar e Nutricional pelo FBSSAN (2019) 65.

Nesse período, a retórica da fome é mobilizada por acadêmicos, partidos, movimentos sociais e mídia e inicia-se um novo momento desse debate. Em 2020, a Pesquisa de Orçamentos Familiares (POF) 2017-2018 14 revela que mais de 10 milhões de brasileiros estavam em situação de insegurança alimentar grave, com maior frequência nas regiões Norte e Nordeste, em domicílios chefiados por mulheres e negros, e com presença de crianças e adolescentes. Com a pandemia de COVID-19 e os desmontes das políticas de segurança alimentar e nutricional, os dados podem ser ainda mais graves.

Por que a fome retorna ao cenário político e social tão rápido? Talvez porque nunca tenha sido efetivamente enfrentada. A estrutura de desigualdades brasileira se manteve 5 mesmo em momentos prósperos. Não falar mais de fome, ou simplesmente dizer que ela acabou, não resolveu a questão. $\mathrm{O}$ uso de diferentes nomenclaturas para falar de fome gerou apagamentos. A retórica política é o que mobiliza auditórios e contribui para invisibilizar aqueles que passam fome, postergando o enfrentamento das situações estruturais que sustentam o modelo de reprodução das desigualdades no país.

Ao destacarmos o uso retórico da fome e a adoção de um sentido mais amplo para ela, como o de insegurança alimentar, indicamos os riscos da manutenção de uma política que não enfrenta as raízes de sua desigualdade e aciona a fome conforme o momento político.

O problema não está em seu uso retórico como insegurança alimentar, mas no apagamento da fome. A política de segurança alimentar e nutricional foi construída e definida a partir da denúncia da fome e do entendimento da complexidade de questões que a envolve. O desenvolvimento da seguran- 
ça alimentar e nutricional foi crucial para avançar em pautas específicas e complexas no campo da alimentação e da nutrição, extrapolando o âmbito setorial e garantindo estratégias efetivas no combate à fome. Assim, a luta pela criação do Consea na década de 1990, a mobilização em torno da segurança alimentar e nutricional com o FBSSAN, mesmo sem a existência do Consea, e a recriação do Consea, em 2003, denotam um esforço de manutenção de uma pauta política em defesa da segurança alimentar e nutricional associada ao combate à fome.

Retirar a pauta da fome do lugar de visibilidade fragiliza a luta política e institucional da segurança alimentar e nutricional e não avança na construção de um projeto de justiça social para o país. Não por acaso, nos dois momentos em que o Consea foi extinto (1995 e 2019), a política de segurança alimentar e nutricional e o combate à fome estiveram fora da pauta política do governo.

Manter essas pautas é condição para garantir o direito constitucional à alimentação tal como previsto na $E C$ no 64/2010. Mas é muito mais do que isso: é manter o compromisso com a vida de pessoas submetidas a situações de absurda indignidade. Enquanto existirem pessoas passando fome no país, não se pode aceitar que a fome acabou. Caso contrário, o tema permanecerá entrando e saindo do debate político, de forma retórica, e continuará sendo uma realidade para tantas pessoas, em números ora maiores, ora menores.

Ressalte-se que estudos que aprofundem o debate de movimentos sociais bem como do processo político propriamente dito poderão trazer contribuições para nossos achados, pois o foco de análise nos sentidos e usos retóricos no debate político certamente não dá conta do debate social, dos conflitos e disputas na formulação de políticas e de uma visão multidimensional da fome.

\section{Colaboradores}

F. R. S. S. Brito e T. W. F. Baptista participaram da redação, análise de documentos e revisão final.

\section{Informações adicionais}

ORCID: Fernanda Ribeiro dos Santos de Sá Brito (0000-0001-6595-4989); Tatiana Wargas de Faria Baptista (0000-0002-3445-2027).

\section{Agradecimentos}

Agradecimento especial à Coordenação de Aperfeiçoamento de Pessoal de Nível Superior (CAPES), que concedeu a bolsa de doutorado, da qual este artigo é desdobramento. 


\section{Referências}

1. Food and Agriculture Organization of the United Nations. The state of food insecurity in the world. Roma: Food and Agriculture Organization of the United Nations; 2014.

2. Instituto Brasileiro de Geografia e Estatística. Pesquisa Nacional por Amostra de Domicílios. segurança alimentar, 2013. Rio de Janeiro: Instituto Brasileiro de Geografia e Estatística; 2014.

3. United Nations Development Programme. Human development report 2015. Copenhagen: United Nations Development Programme; 2015.

4. Instituto Brasileiro de Geografia e Estatística. Pesquisa Nacional por Amostra de Domicílios contínua, 2018. Rio de Janeiro: Instituto Brasileiro de Geografia e Estatística; 2019.

5. Souza PHGF. Uma história de desigualdade: a concentração de renda entre os ricos no Brasil, 1926-2013. São Paulo: Hucitec Editora; 2018.

6. Sardinha LMV, Campos R, Pires PS, Jannuzzi P. Análise das condições de vida, segurança alimentar e nutricional e acesso a programas sociais em comunidades quilombolas tituladas. Cadernos de Estudos: Desenvolvimento Social em Debate 2014; (20):31-52.

7. L'Abbate S. As políticas de alimentação e nutrição no Brasil. I. Período de 1940 a 1964. Rev Nutr PUCCAMP 1988; 1:87-138.

8. Castro J. Geografia da fome - o dilema brasileiro: pão ou aço. Rio de Janeiro: Antares;1984.

9. Sallum Jr. B. Crise, democratização e liberalização no Brasil. In: Sallum Jr. B, organizador. Brasil e Argentina hoje: política e economia. Bauru: EdUSC; 2004. p. 40-59.

10. Peliano AMT. O mapa da fome: subsídios à formulação de uma política de segurança alimentar. Brasília: Instituto de Pesquisa Econômica Aplicada; 1993.

11. Instituto Cidadania. Projeto Fome Zero: uma proposta de política de segurança alimentar para o Brasil. São Paulo: Instituto Cidadania; 2001.

12. Magalhães R. Renda per capita inferior a 1,25 dólar por dia. Aumenta a fome e a insegurança alimentar no Brasil. São Leopoldo: Instituto Humanitas Unisinos; 2017.

13. Grupo de Trabalho da Sociedade Civil para Agenda 2030. Relatório Luz da Agenda 2030 de desenvolvimento sustentável - síntese. https://brasilnaagenda2030.files.wordpress. com/2017/07/relatorio-luz-gtsc-brasil-hlpf 2017.pdf (acessado em 21/Jan/2019).

14. Cabral U. 10,3 milhões de pessoas moram em domicílios com insegurança alimentar grave. Agência IBGE de Notícias 2020; 17 set. https://agenciadenoticias.ibge.gov.br/agen cia-noticias/2012-agencia-de-noticias/noti cias/28903-10-3-milhoes-de-pessoas-moramem-domicilios-com-inseguranca-alimentargrave.

15. Monteiro CA. Fome, desnutrição e pobreza: além da semântica. Saúde Soc 2003; 12:7-11.
16. Freitas MC. Agonia da fome. Salvador: EdUFBA/Rio de Janeiro: Editora Fiocruz; 2003.

17. Spink MJP, Medrado B. Produção de sentido no cotidiano: uma abordagem teórico-metodológica para análise das práticas discursivas. In: Spink MJ, organizador. Práticas discursivas e produção de sentidos no cotidiano: aproximações teóricas e metodológicas. São Paulo: Cortez Editora; 2013. p. 41-61.

18. Perelman C. Retóricas. São Paulo: Martins Fontes; 1997.

19. Minayo MCS. Raízes da fome no Brasil. Rio de Janeiro: Vozes Editora;1986.

20. Singer P. Evolução da economia e vinculação internacional. In: Sachs I, Wiheim J, Pinheiro PS, organizadores. Brasil: um século de transformações. São Paulo: Companhia das Letras; 2001. p. 78-131.

21. Minayo MCS. A saúde em estado de choque. Petrópolis: Espaço e Tempo/Fase; 1986.

22. Instituto Nacional de Alimentação e Nutrição. I Conferência Nacional de Alimentação e Nutrição. Relatório final. Brasília: Instituto $\mathrm{Na}$ cional de Alimentação e Nutrição/Ministério da Saúde;1986.

23. Maluf RSJ. Segurança alimentar e nutricional. Petrópolis: Editora Vozes; 2007.

24. Silva JG, Silva LIL. Sem medo de trabalhar na terra: uma visão popular da agricultura brasileira. São Paulo: Governo Paralelo/Partido dos Trabalhadores; 1991.

25. Câmara de Deputados. Projeto de Resolução no 84, de 1991. https://www.camara.leg.br/pro posicoesWeb/prop_mostrarintegra;jessioni $\mathrm{d}=9$ BDFAED8747948CA1C73AFB4391440AD. proposicoesWeb2 ? codteor $=1243740 \&$ filena me $=$ Dossie+-PRC+84/1991+CPIFOM (acessado em 21/Dez/2018).

26. Pandolfi D, Gazir A, Corrêa L. O Brasil de Betinho. Rio de Janeiro: Mórula Editorial; 2012.

27. Burlandy L. A atuação da sociedade civil na construção do campo da Alimentação e Nutrição no Brasil: elementos para reflexão. Ciênc Saúde Colet 2011; 16:63-72.

28. Conselho Nacional de Segurança Alimentar e Nutricional. I Conferência Nacional de Segurança Alimentar. Relatório final. Brasília: Conselho Nacional de Segurança Alimentar e Nutricional; 1994.

29. Cardoso FH. Mãos à obra, Brasil: proposta de governo. Rio de Janeiro: Centro Edelstein de Pesquisas Sociais; 2008.

30. Reis DA. A vida política. In: Reis DA, organizador. Modernização, ditadura e democracia: 1964-2010. Rio de Janeiro: Objetiva; 2014. p. 75-126.

31. Partido dos Trabalhadores. Lula presidente: uma revolução democrática no Brasil. Bases do programa de governo. https://fpabramo.org. $\mathrm{br} / \mathrm{csbh} /$ programas-de-governo/ (acessado em 21/Jan/2019). 
32. Pinheiro ARO, Carvalho MFCC. Transformando o problema da fome em questão alimentar e nutricional: uma crônica desigualdade social. Ciênc Saúde Colet 2010; 15:121-30.

33. Presidência da República. Comunidade solidária: todos por todos. http://www.biblioteca. presidencia.gov.br/publicacoes-oficiais/cata logo/fhc/comunidade-solidaria-todos-por-to dos-1996/@@download/file/Comunidade\%20 solid\%C3\%A1 ria\%20-\%20todos\%20por\%20 todos\%20-\%201996.pdf (acessado em 18/ Dez/2018).

34. Fagnani E. Ajuste econômico e financiamento da política social brasileira: notas sobre o período 1993/98. Economia e Sociedade 1999; 13:155-78.

35. Garcia DV. A construção de arranjos institucionais intersetoriais no governo federal (2003 a 2006): um estudo a partir da produção do Executivo Presidência [Tese de Doutorado]. Niterói: Universidade Federal Fluminense; 2014.

36. Cardoso FH. Avança, Brasil: proposta de governo. Rio de Janeiro: Centro Edelstein de Pesquisas Sociais; 2008.

37. Fundação Perseu Abramo; Partido dos Trabalhadores. Programa de governo 1998. Carta de compromisso. https://fpabramo.org.br/csbh/ programas-de-governo/ (acessado em 21/Jan/ 2019).

38. Fundação Perseu Abramo; Partido dos Trabalhadores. Diretrizes de governo. 1. Caderno de Agricultura. https://fpabramo.org.br/csbh/ programas-de-governo/ (acessado em 21/Jan/ 2019).

39. Fundação Perseu Abramo; Partido dos Trabalhadores. União do povo - muda Brasil. https://fpabramo.org.obr/csbh/programas-degoverno/ (acessado em 21/Jan/2019).

40. Draibe S. A política social no período FHC e o sistema de proteção social. Tempo Social 2003; 15:63-103.

41. Valente FLS. A política de insegurança alimentar e nutricional. In: Rocha D, Bernardo M, organizadores. A era FHC e o governo Lula: transição? Brasília: Editora do Instituto de Estudos Socioeconômicos; 2004. p.391-420.

42. Almeida MHT. A política social no governo Lula. Novos Estudos Cebrap 2004; 70:7-17.

43. Pessanha LDR. A experiência brasileira em políticas públicas para a garantia do direito ao alimento. Rio de Janeiro: Instituto Brasileiro de Geografia e Estatística; 2002.

44. Fundação Perseu Abramo; Partido dos Trabalhadores. Programa de governo 2002. https:// fpabramo.org.br/csbh/programas-de-governo/ (acessado em 21/Jan/2019).

45. Carreirão Y. A eleição presidencial de 2002: uma análise preliminar do processo e dos resultados eleitorais. Revista de Sociologia Política 2004; (22):179-94.
46. Presidência da República. Pronunciamento do Presidente da República, Luiz Inácio Lula da Silva, na sessão solene de posse no Congresso Nacional. http://www.biblioteca.presidencia. gov.br/presidencia/ex-presidentes/luiz-inacio -lula-da-silva/discursos/discursos-de-posse/ discurso-de-posse-1o-mandato (acessado em 20/Ago/2019).

47. Tomazini CG, Leite CKS. Programa Fome Zero e o paradigma da segurança alimentar: ascensão e queda de uma coalizão? Revista de Sociologia e Política 2016; 24:13-30.

48. Comitê de Entidades no Combate à Fome e pela Vida. Das ruas às redes: 15 anos de mobilização social na luta contra a fome e a pobreza. Rio de Janeiro: Rede Nacional de Mobilização Social; 2008.

49. Betto F. Programa Fome Zero - como participar. Cartilha da Mobilização Social. http:// www.dominiopublico.gov.br/download/texto/ ue000083.pdf (acessado em 25/Ago/2019).

50. Betto F. O calendário do poder. Rio de Janeiro: Rocco Editora; 2007.

51. Silva JG, Takagi M. Fome Zero: política pública e cidadania. In: Rocha M, organizador. Segurança alimentar: um desafio para acabar com a fome no Brasil. São Paulo: Fundação Perseu Abramo; 2004. p. 41-61.

52. Conselho Nacional de Segurança Alimentar e Nutricional. II Conferência Nacional de Segurança Alimentar e Nutricional - a construção da Política Nacional de Segurança Alimentar e Nutricional. Relatório final. https://bvsms. saude.gov.br/bvs/publicacoes/II_Conferen cia_2versao.pdf (acessado em 25/Set/2019).

53. Brasil. Decreto no 7.272 , de 25 de agosto de 2010. Regulamenta a Lei no 11.346 , de 15 de setembro de 2006, que cria o Sistema Nacional de Segurança Alimentar e Nutricional SISAN. Diário Oficial da União 2010; 26 ago.

54. Brasil. Lei no 11.346 , de 15 de setembro de 2006. Cria o Sistema Nacional de Segurança Alimentar e Nutricional - SISAN com vistas em assegurar o direito humano à alimentação adequada e dá outras providências. Diário Oficial da União 2006; 18 set.

55. Brasil. Emenda Constitucional no 64, de 4 de fevereiro de 2010. Altera o art. 6o da Constituição Federal, para introduzir a alimentação como direito social. Diário Oficial da União 2010; 4 fev.

56. Conselho Nacional de Segurança Alimentar e Nutricional. III Conferência Nacional de Segurança Alimentar e Nutricional - por um desenvolvimento sustentável com soberania e segurança alimentar e nutricional. Relatório final. http://www4.planalto.gov.br/consea/ eventos/conferencias/arquivos-de-conferen cias/3a-conferencia-nacional-de-seguranca-a limentar-e-nutricional/relatorio-final-iii-con ferencia-nacional-de-seguranca-alimentar-enutricional.pdf (acessado em 25/Set/2019). 
57. Ministério do Desenvolvimento Social. Bolsa família: cidadania e dignidade para milhões de brasileiros. Revista especial. https://datas pace.princeton.edu/handle/ $88435 / \mathrm{dsp} 01 \mathrm{j}$ q085n248 (acessado em 21/Set/2019).

58. Ministério do Desenvolvimento Social. Plano Brasil sem Miséria - caderno de resultados. http://www.mds.gov.br/webarquivos/pu blicacao/brasil_sem_miseria/cadernode graficosbsm-35anos.pdf (acessado em 21/ Set/2019).

59. Ministério do Desenvolvimento Social. Plano Brasil sem miséria. Ficha-resumo. https:// wwp.org.br/wp-content/uploads/2016/12/ wwp_ficha-resumo_bsm_brasil_sem_mise ria_portugues.pdf (acessado em 23/Set/2019).

60. Ministério da Saúde. Política Nacional de Alimentação e Nutrição. https://bvsms.saude. gov.br/bvs/publicacoes/politica_nacional_ali mentacao_nutricao.pdf (acessado em 15/ Out/2019).

61. Conselho Nacional de Segurança Alimentar e Nutricional. IV Conferência Nacional de Segurança Alimentar e Nutricional. Relatório final. https://www.ipea.gov.br/participacao/ images/pdfs/conferencias/Seguranca_alimen tar_IV/relatorio_preliminar_4_conferencia_ seguranca_alimentar_nutricional.pdf (acessado de 02/Out/2019).
62. Conselho Nacional de Segurança Alimentar e Nutricional. V Conferência Nacional de Segurança Alimentar e Nutricional. Relatório final. Brasília: Conselho Nacional de Segurança Alimentar e Nutricional/Ministério do Desenvolvimento Social; 2015.

63. Instituto Brasileiro de Geografia e Estatística. Pesquisa Nacional por Amostra de Domicílios Contínua. Notas técnicas. Rio de Janeiro: Instituto Brasileiro de Geografia e Estatística; 2020.

64. Brasil. Emenda Constitucional no 95 de 15 de dezembro de 2016. Altera o Ato das Disposições Constitucionais Transitórias, para instituir o Novo Regime Fiscal, e dá outras providências. Diário Oficial da União; 2016.

65. Santarelli M, David G, Burity V, Rocha NC. Informe Dhana 2019: autoritarismo, negação de direitos e fome. Brasília: FIAN Brasil; 2019. 


\section{Abstract}

Hunger is a persistent and structural issue in Brazil, occupying space intermittently on the political agenda, especially in times of political crisis. But when does it become interesting to denounce hunger? Who enunciates the problem and how? The article discusses the different discursive uses and meanings associated with hunger in Brazil's political debate from 1986 to 2015 and sheds light for updating the debate since 2016. This is a policy analysis study that aims to back reflection on the strategies and objectives of recent public policies to fight hunger in Brazil. The study analyzed government policy documents related to hunger from 1986 to 2015, revealing different meanings of hunger that were mobilized politically at different moments in the Brazilian context. Hunger was viewed variably as nutritional deficiency, poverty, destitution, social injustice, inequality, and food insecurity. As for political uses, hunger was mobilized discursively by different actors, according to the scenario of political dispute, until it practically disappeared from the debate, only to return during a new crisis in 2016. The return to the debate also reflects the failure to deal with structural inequalities. When hunger lost space on the political agenda, food and nutritional security policy was also undermined, and many gains were lost. The article concludes that the political discourse on hunger mobilizes audiences and is important to keep the fight against hunger in the political debate so long as there are people going hungry in the country. This should be a central item on the agenda to guarantee food and nutritional security.

Hunger; Food Insecurity; Food Security; Public Policy

\section{Resumen}

El hambre es una cuestión persistente y estructural en Brasil, ocupando espacio en la agenda política cada cierto tiempo, en especial en momentos de crisis política. Sin embargo, ¿cuándo se hace interesante denunciar el hambre? ¿Quién enuncia el problema y de qué modo? El artículo discute los diferentes usos retóricos y sentidos asociados al hambre en el debate político brasileño, durante el periodo de 1986 a 2015, y proyecta luz hacia la reactualización del debate a partir de 2016. Se trata de un estudio de análisis de politicas que tiene por objetivo apoyar la reflexión sobre las estrategias y objetivos de las políticas públicas de combate al hambre en Brasil recientemente. La investigación analizó documentos relacionados con el hambre, referidos a la politica gubernamental de 1986 a 2015, revelando diferentes sentidos del hambre activados políticamente en momentos distintos del contexto brasileño. El hambre vista como carencia nutricional, pobreza, miseria, injusticia social, desigualdad e inseguridad alimentaria grave. En cuanto a los usos politicos, el hambre fue movilizada retóricamente por diferentes actores conforme el escenario de disputa política, hasta prácticamente desaparecer del debate, volviendo otra vez a partir de una nueva crisis en el año de 2016. Este regreso también se refiere al no enfrentamiento de las desigualdades estructurales. Cuando el hambre perdió su espacio en la agenda política, se fragilizó también la política de seguridad alimentaria $y$ nutricional y muchas conquistas conseguidas retrocedieron. Se concluye que la retórica política moviliza auditorios, siendo importante mantener la pauta de combate al hambre en el debate politico, mientras existan personas pasando hambre en el país, debiendo ser esta una agenda central para la garantía de la seguridad alimentaria y nutricional.

Hambre; Inseguridad Alimentaria; Seguridad Alimentaria; Política Pública
Recebido em 25/Out/2020

Versão final reapresentada em 08/Fev/2021

Aprovado em 18/Fev/2021 